tion, is precisely the purport of this message,-an appeal for any form of prosthetic dentistry which does not spell ultimate invalidism to those who through neglect of dental diseases have to avail themselves of it. Indirectly, please interpret our remarks as an urgent entreaty for the conservation of the dental pulp, not perhaps so much for the sake of maintaining the vitality of the dentin, but because its disappearance through disease or to subserve prosthetic purposes carries with it complications of so serious a nature as to warrant the statement that the loss of a pulp through any cause, marks a tragic epoch in the individual's existence.

\title{
REPORT OF A CASE OF DENTIGEROUS CYST OF THE MANDIBLE IN WHICH THE X-RAY PROVED OF GREAT VALUE
}

\author{
By E. F. Tholen, M.D., D.D.S., Los AngEles, CaL.
}

W. E. Age 16. Male.

History.-Two years ago noticed pain and swelling over center of lower jaw. This was incised through the mouth and drained. Pus obtained. Symptoms subsided after six days. Patient stated that radiograph made at that time showed nothing abnormal. The same condition has recurred twice. The lower centrals and laterals have always been sensitive and at times quite loose.

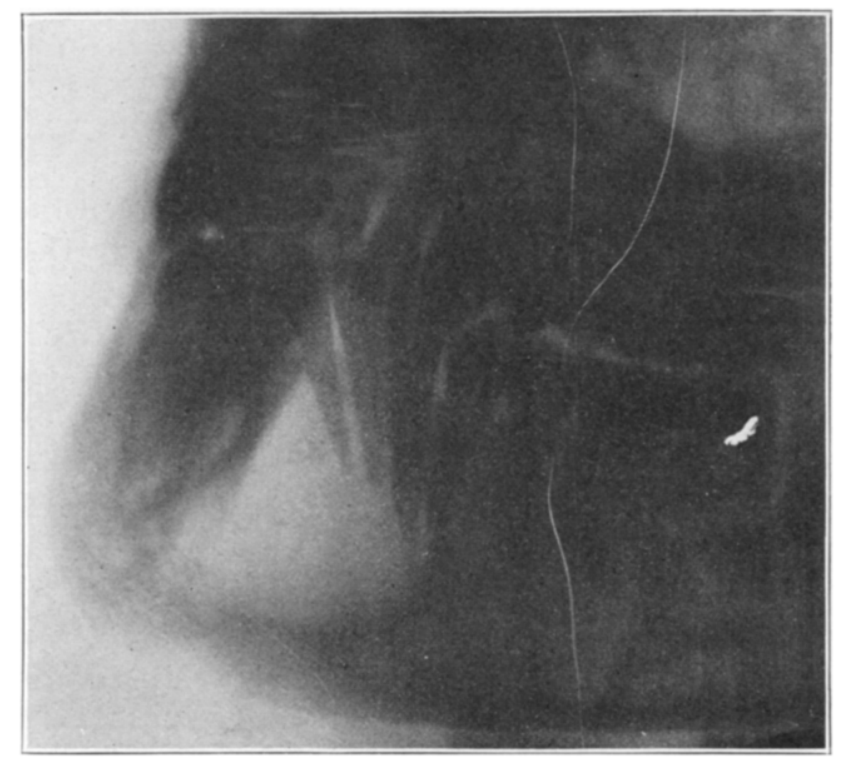

Fig. 1.-Radiograph showing the extent of the cyst on the left side of the median line.

The last attack began January 26 , with pain, tenderness, temperature and swelling of anterior third of lower jaw. It was lanced through the mouth two days later, and an offensive pus obtained. Five days later I saw the patient. Ex- 
amination showed bulging of the lingual plate of the mandible, crowding the tongue backwards and interfering with speech. There were no signs of an acute inflammation. The centrals and laterals were displaced foreward, quite loose, tender to pressure, and sensitive to cold. There was an incised wound in the labial fold that discharged a yellowish watery fluid. Probing wound led to normal bone. The soft tissues over the mental region were infiltrated. The external surface of the mandible appeared normal. Radiograph shows a cyst extending from bicuspid to bicuspid involving the entire thickness of the mandible from the alveolus to the lower border. The roots of the laterals and centrals were in the cyst. (See Figs. 1 and 2.)

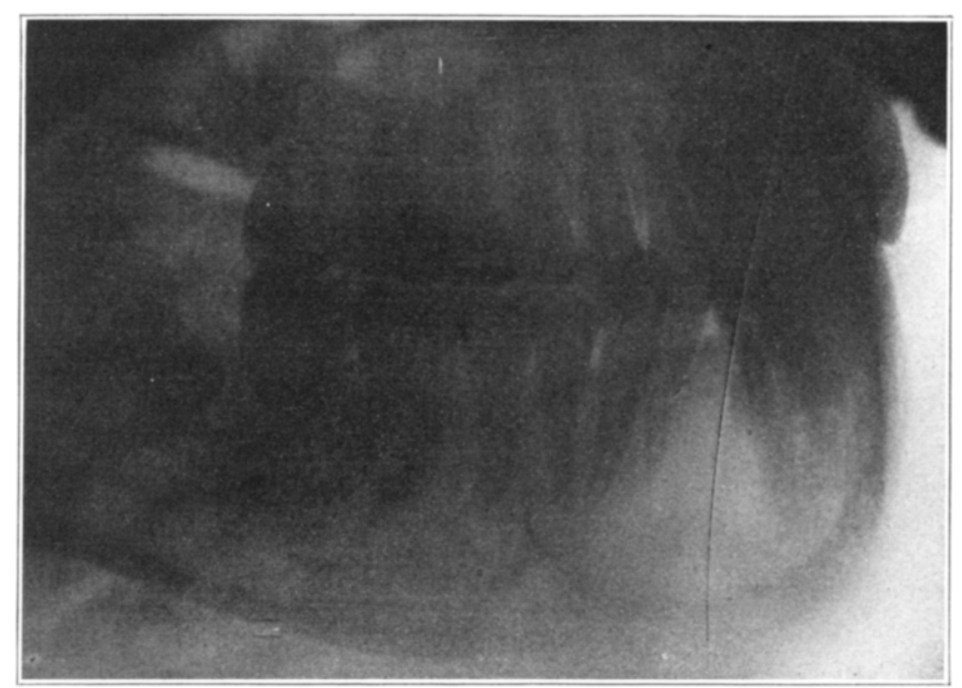

Fig. 2.-The extent of the cyst on the right side of the median line is here shown.

Treatment.- The lower centrals and laterals were extracted and an incision made distally and lingually from sockets to the first bicuspids. The lingual mucoperiosteum was elevated and the underlying wall removed with chisel and biting forceps. The anterior wall of the cyst was left intact and made flush with surrounding mandible. The wound was packed. The patient made an excellent recovery.

Examination of the cyst wall showed it to be made up of dense connective tissue and lined by a layer of squamous epithelium which was infiltrated with small round cells. 